\title{
Fuzzy Comprehensive Evaluation of Coal Logistics Development Level under New Policy Environment
}

\author{
Hongmei Ju ${ }^{\mathrm{a}}$, Qiqi Liu ${ }^{\mathrm{b}}$, Wei Yin ${ }^{\mathrm{c}}$ \\ School of Beijing Wuzi University, Beijing 101100, China. \\ ajuhongmei@bwu.edu.cn, bYoloDaisy@163.com, c1533933270@qq.com
} Keywords: Reform of The Majority System; One Belt One Road; Coal Logistics; Fuzzy Clustering;
Secondary Fuzzy Comprehensive Evaluation.

\begin{abstract}
As a large energy consuming country, coal resources play a pivotal role in China's economic development. And coal logistics as a balance of China's uneven distribution of energy the main means, its importance is self-evident. In 2013, the "one way along the way" strategy, China's various infrastructure has been improved, the level of foreign economic and trade has increased significantly. 2015, "one way all the way" strategy, China's various infrastructure continue to improve, foreign economic and trade level was significantly enhanced. Combined with the new policy on the development of China's coal logistics, this paper first established China's coal logistics evaluation index system, the use of fuzzy clustering method of China's eight major coal provinces, autonomous regions into several categories. Then the two-level fuzzy comprehensive evaluation model is used to judge and analyze the clustering results, and the development level of coal logistics is obtained. Finally, the future development of China's coal logistics made recommendations.
\end{abstract}

\section{Introduction}

\subsection{The Significance of Coal Logistics in the New Policy Traffic Environment}

According to China National Bureau of Statistics 2016 statistics, in 2015 China's total energy production reached 362 million tons of standard coal, of which coal production accounted for the proportion of total energy production reached $72.1 \%$. Also in 2015, China's total energy consumption of 43 million tons of standard coal, coal consumption accounted for up to $64 \%$. However, such a rich coal resources are not evenly distributed in China's provinces, autonomous regions, China's coal resources, the overall distribution of the northwest, southeast less distribution pattern. The distribution of resources determines the spatial pattern of coal production in China. Specifically, China's coal production is concentrated in the Yellow River Basin in Shanxi, Shaanxi, near Inner Mongolia, as well as Xinjiang, Guizhou and other places part of the coal production. And the distribution of coal resources is very different, China's coal demand is mainly determined by the level of regional economic development. As the southeast coast of China and the Beijing-Tianjin-Tangzhuang industrial zone economic development level is much higher than the central and western regions, so the eastern region, especially the southeastern region has become China's major coal demand. Therefore, the pattern of domestic coal consumption is more southeast, northwest less.

As a result, China's coal transport is usually from west to east, from north to south. This longdistance, multi-transshipment transport demand determines the important position of China's coal logistics, making China's coal logistics pattern for the West coal transport, North coal mine.

Reasonable regulation of China's coal resources supplies and demand imbalance, depends on our further development and optimization of coal logistics.

On the other hand, the great changes in national policy also affect the development of China's coal logistics. In March 10, 2013, China's State Council announced the "State Council institutional reform and functional transformation program", which began a new system of reform. Such a move to a large extent to avoid cross-government functions, government more than a number of management and other issues, in order to achieve lower costs and improve the efficiency of administrative results. In terms of transportation, the original Ministry of Railways is no longer retained, the implementation of railway government and government separately. As the main mode of transport of coal logistics, 
the transformation of railway administration has had a great impact on China's coal logistics. For example, China's coal cargo transport volume, coal cargo turnover, etc. have been compared before have produced a greater change.

On March 28, 2015, the National Development and Reform Commission, the Ministry of Foreign Affairs and the Ministry of Commerce jointly issued the "Vision and Action to Promote the Economic Development of the Silk Road and the Maritime Silk Road in the 21st Century". "With the way" strategy for the implementation of China's energy resources and the development of the level of transportation has a more significant significance. The construction of a number of infrastructure projects such as railway and natural gas pipelines in China and Europe has greatly improved the infrastructure level of China's coal logistics, such as the increase of railway mileage, which has provided the development opportunity for China's coal logistics once again.

\subsection{The Concept and Research Status of Coal Logistics}

The concept of logistics was born in the 1990s, initially from military logistics. In simple terms, logistics refers to the flow of goods. All the time, the scholars of the definition of the logistics of the word, the views of different schools is not uniform. Coal logistics as a logistics of a special way of transport, in terms of the same broad sense of the basic composition of the logistics, but on the other hand, coal logistics also has its own characteristics. For example, in addition to our ordinary logistics functions, but also includes the washing process, the comprehensive utilization of waste and so on. At present, the coal logistics is more recognized that the coal logistics is divided into coal production logistics, coal sales logistics and coal recycling logistics.

Due to the important position of coal resources in China's resource strategy and the importance of logistics industry in recent years, the related research has been gradually increased in recent years. In 1991, Qianjie Ma in the coal business logistics[1] from the logistics and coal production and management point of view, discusses how the coal business logistics management; In 1995, Zhishan Ma made an analysis and analysis of the cost of coal logistics in the study of reducing the cost of coal supply logistics[2];In 2003, Dapeng Zhang, Yong He and Shenfeng Jing provided suggestions for the logistics informationization of coal enterprises in the article Realization of logistics informationization of coal enterprises[3], and suggested that the role of ERP in the logistics of coal enterprises should be pragmatic; The National Development and Reform Commission and the National Energy Board in 2014 customized the coal logistics development plan[4], its development plan contains the 2020 development goals;2015 Yinying Tang, Jiaxin Sun and so on in the "railway" door to door "full logistics service customer satisfaction evaluation" [5] in the use of fuzzy comprehensive evaluation of the railway logistics customer satisfaction evaluation and an empirical analysis;2015,Economic Daily published an article entitled new opportunities for coal logistics industry [6] article, further analysis of the bulk of the traffic environment Carbon logistics development of the positive factors; Shijiazhuang Railway University Wang Zhaoyu in the article under the majority of the system under the Hebei railway government management new model[7], the new policy situation and the further development of the railway made an analysis; Beijing Jiaotong University Haiping $\mathrm{Lu}$ in the railway freight embedded social logistics model and operational mechanism research[8] and Beijing Jiaotong University Bo Wang in the market conditions under the conditions of railway freight competition strategy selection and optimization of transport resources[9] are on the railway in the Social logistics plays a role and role in the analysis and so on. But at the same time, according to the National Bureau of Statistics and the National Logistics Information Network and the relevant data and data show that China's coal logistics tax increases, the cost of further increase. China Railway Corporation in the market competition environment profitability obvious. China's coal logistics is still in the transition stage, whether the direction of intensive and modern changes in a critical period.

\section{Comprehensive Evaluation Index System of Coal Logistics}

In today's new policy and economic environment, we need a new assessment of the regional coal logistics to assess the level of its logistics development, so as to more comprehensive and in-depth 
understanding of China's coal logistics development, and according to different levels of coal logistics regional development Level to develop the future direction of the city or regional development.

According to the latest statistical data of coal reserves and production and sales of provinces and cities in China, this paper selects eight important coal provinces and autonomous regions to carry out regional coal logistics comprehensive evaluation, namely: Inner Mongolia, Shanxi, Shaanxi, Xinjiang, Guizhou, Shandong, Henan, Anhui. At the same time, on the basis of the previous scholars 'research, the experts' opinions are consulted, and the following aspects are selected to establish the comprehensive evaluation index system of regional coal logistics development level. These indicators reflect the development characteristics of regional coal logistics from various aspects.

\subsection{Internal index of coal logistics industry}

(1) coal logistics scale indicators: coal logistics industry output value, coal logistics industry transport volume, coal cargo turnover, coal reserves;

(2) coal logistics human resources indicators: the number of coal logistics practitioners, coal logistics practitioners in the proportion of college and above;

(3) infrastructure indicators: railway mileage, coal logistics industry, fixed investment, coal inventory turnover rate;

(4) coal logistics structure indicators: coal logistics industry output value of GDP;

(5) coal logistics contribution index: economic contribution rate, employment contribution rate;

(6) coal logistics development potential indicators: coal logistics industry value-added growth rate, coal logistics industry practitioners' growth rate.

\subsection{External index of coal logistics industry}

(1) the level of economic development indicators: GDP, per capita GDP, the proportion of the tertiary industry;

(2) information and communication construction indicators: the total number of post and telecommunications services, the number of households in the city, the number of mobile phones, the number of Internet users;

(3) production and circulation indicators: per capita industrial output value, more than 100-millionyuan commodity trading market turnover, total retail sales of social consumer goods

\section{The Fuzzy Clustering Model Is Established}

As the provinces and autonomous regions between the coal logistics development level is not the same, so we must first of these eight provinces, autonomous regions, classification, logistics development level is more similar to a class. Based on the comprehensive evaluation index system of coal logistics established in the previous section, we use the specific indexes of provinces and autonomous regions to establish fuzzy matrix, and then classify them.

\subsection{Data Standardization}

With the original matrix $R=\left[\begin{array}{cccc}X_{11} & X_{12} & \cdots & X_{1 n} \\ X_{21} & X_{22} & \cdots & X_{2 n} \\ \vdots & \vdots & \ddots & \vdots \\ X_{m 1} & X_{m 2} & \cdots & X_{m n}\end{array}\right]$

$X_{i k}$ represents the $k$ th indicator of the $i$ th province. Such as $x_{11}$ that China's Inner Mongolia Autonomous Region of the coal logistics industry output value.

Because of the actual problem, different data generally have different dimensions. For example, in this model, the economic contribution rate of the coal logistics development level is different from that of the railway mileage index. In order to compare the amount of different dimensions, it is necessary to eliminate the influence of the original data dimension:

$\bar{X}$ is the mean, $S$ is the variance

$$
X_{i k}^{\prime}=\frac{\left(X_{i k}-\bar{X}\right)}{S_{k}}(i=1,2, \cdots, n ; k=1,2, \cdots, m)
$$

At the same time in order to ensure that $x_{i k}^{\prime}$ in the interval $[0,1]$, the translation of the extreme conversion. 


$$
x_{i k}^{\prime \prime}=\frac{x_{i k}^{\prime}-\min \left\{x_{i k}^{\prime}\right\}}{\max \left\{x_{i k}^{\prime}\right\}-\min \left\{x_{i k}^{\prime}\right\}}(k=1,2, \cdots, m)
$$

So that $0 \leq x_{i k}^{\prime \prime} \leq 1$, but also eliminates the effect of the dimension.

\subsection{Create Fuzzy Similarity Matrix}

In order to measure the degree of similarity between them, calculate the similarity statistics

$r_{i j}=R\left(x_{i}, x_{j}\right), \quad 0 \leq r_{i j} \leq 1$

Create fuzzy similarity matrix:

$$
R^{\prime}=\left[\begin{array}{cccc}
r_{11} & r_{12} & \cdots & r_{1 n} \\
r_{21} & r_{22} & \cdots & r_{2 n} \\
\vdots & \vdots & \ddots & \vdots \\
r_{m 1} & r_{m 2} & \cdots & r_{m n}
\end{array}\right]
$$

In this paper, we use the maximum and minimum method to calculate the sample of similar statistics:

$$
r_{i j}=\frac{\sum_{k=1}^{m}\left(x_{i k} \wedge x_{j k}\right)}{\sum_{k=1}^{m}\left(x_{i k} \vee x_{j k}\right)}
$$

\subsection{The Fuzzy Equivalent Matrix Is Established By Means Of Transitive Closure}

$$
\mathrm{R} \rightarrow \mathrm{R}^{2} \rightarrow \mathrm{R}^{4} \cdots \rightarrow \mathrm{R}^{2 \mathrm{n}}
$$

\subsection{Identify Different Thresholds And Cluster Them}

In the fuzzy clustering analysis, for each different, different classification can be obtained, thus forming a dynamic clustering map. There are usually two ways to determine the optimal threshold, one is based on actual needs, in the dynamic clustering map, adjust the value to get the appropriate classification, the other is the focus of this article to take the best use of F statistics to determine the best value.

Set the domain $U=\left\{x_{1}, x_{2}, \cdots, x_{n}\right\}$ to the sample space (the total number of samples is $n$ ), and each sample $x_{i}$ has $m$ characteristics (ie, data obtained by experiment or observation): $x_{i}=$ $\left(x_{i 1}, x_{i 2}, x_{i 3}, \cdots, x_{i m}\right)(i=1,2, \cdots, n)$. Then get the original data matrix, as shown in the table below, Where $\overline{x_{k}}=\frac{1}{n} \sum_{i=1}^{n} x_{i k}(k=1,2, \cdots, m), \bar{x}$ is called the central vector of the population sample.

$$
R=\left[\begin{array}{cccc}
X_{11} & X_{12} & \cdots & X_{1 n} \\
X_{21} & X_{22} & \cdots & X_{2 n} \\
\vdots & \vdots & \ddots & \vdots \\
X_{m 1} & X_{m 2} & \cdots & X_{m n}
\end{array}\right]
$$

Suppose that the number of classes corresponding to $\lambda$ is $r$, the number of samples of class $j$ is $n_{j}$, and the sample of class $j$ is denoted as:

$$
\mathrm{F}=\frac{\sum_{j=1}^{r} n_{j}\left\|\overline{x^{(J)}}-\bar{x}\right\|^{2} /(r-1)}{\sum_{j=1}^{r} \sum_{i=1}^{n_{j}}\left\|x_{i}^{(j)}-\overline{x^{(J)}}\right\|^{2} /(n-r)}
$$

Where $\left\|\overline{x^{(J)}}-\bar{x}\right\|=\sqrt{\sum_{k=1}^{m}\left(\overline{x_{k}^{(J)}}-\overline{x_{k}}\right)^{2}}$ is the distance between $\overline{x^{(J)}}$ and $\bar{x},\left\|x_{i}^{(j)}-\overline{x^{(J)}}\right\|$ is the distance between the $i$-th sample $x_{i}^{(j)}$ and its center $\bar{x}^{(j)}$ in the jth class. F statistic obeys the F distribution of degrees of freedom of $r-1, n-r$. Its numerator characterizes the distance between classes and classes, and the denominator characterizes the distance between classes. So the greater the $\mathrm{F}$ value, indicating the greater the distance between the class and class; the greater the difference between class and class, the better the classification

If $F>F_{\alpha}(r-1, n-r)(\alpha=0.05)$, according to mathematical statistics analysis of variance analysis theory that the difference between class and class is significant, then the classification is reasonable. If you meet the inequality $F>F_{\alpha}(r-1, n-r) \mathrm{F}$ value of more than one, you can further study the size of the difference ratio $\left(F-F_{\alpha}\right) / F_{\alpha}$, from the larger to find a satisfactory $\mathrm{F}$ value on the line. 


\section{Two-Level Fuzzy Comprehensive Evaluation}

In the eight provinces, autonomous regions, fuzzy clustering, we need to have a good class of fuzzy comprehensive evaluation, the purpose is to determine the level of its different coal logistics development.

The average value of several different indexes is calculated, and the calculated average value is used as the factor set to carry out fuzzy comprehensive evaluation. As a result of the coal logistics evaluation process we have established a multi-level indicator, so the main introduction of two levels of the model - two models, the specific steps are as follows:

\subsection{Set Factor Set}

The establishment of factor set $U=\left\{u_{1}, u_{2}, \cdots, u_{n}\right\}$, factor set factor is the logistics development level of indicators in the evaluation index system.

Will factor set $U=\left\{u_{1}, u_{2}, \cdots, u_{n}\right\}$ divided into several groups $U=\left\{U_{1}, U_{2}, \cdots, U_{k}\right\}$, making

$\mathrm{U}=\mathrm{U}_{i=1}^{k} U_{i}, U_{i} \cap U_{j}=\emptyset(i \neq j)$

Called $U=\left\{U_{1}, U_{2}, \cdots, U_{k}\right\}$ for a factor set.

Set $U_{i}=\left\{u_{1}^{(i)}, u_{2}^{(i)}, \cdots, u_{n_{i}}^{(i)}\right\}(i=1,2, \cdots, k)$

Among them, $n_{1}+n_{2}+\cdots n_{k}=\sum_{i=1}^{k} n_{i}=n$

Called the second factor set.

\subsection{Establish a set of Judgments}

Establish a judgment set $V=\left\{v_{1}, v_{2}, \cdots, v_{m}\right\}$. In the judging of the development level of coal logistics in different provinces, we can show that the level of logistics development has a high level, middle level, low level of the points. The $n_{i}$ factor of the $U_{i}=\left\{u_{1}^{(i)}, u_{2}^{(i)}, \cdots, u_{n_{i}}^{(i)}\right\}$ factor of the secondary factor set is judged by the single factor, that is, the fuzzy mapping is established. Thus the single factor judgment matrix is

$$
R_{i}=\left(\begin{array}{ccc}
r_{11}^{(i)} & \cdots & r_{1 m}^{(i)} \\
\vdots & \ddots & \vdots \\
r_{n_{i} 1}^{(i)} & \cdots & r_{n_{i} m}^{(i)}
\end{array}\right)_{n_{j} \times m}
$$

Set the weight of $U_{i}=\left\{u_{1}^{(i)}, u_{2}^{(i)}, \cdots, u_{n_{i}}^{(i)}\right\}$ to $A=\left(a_{1}^{(i)}, a_{2}^{(i)}, \cdots, a_{n_{i}}^{(i)}\right)$

Get a comprehensive judgment for $A_{i} \circ R_{i}=B_{i}(i=1,2, \cdots, k)$

\subsection{The First Level of Factors for Comprehensive Evaluation}

On the first factor set $U=\left\{U_{1}, U_{2}, \cdots, U_{k}\right\}$ for comprehensive evaluation.

Let $U=\left\{U_{1}, U_{2}, \cdots, U_{k}\right\}$ the weight of $A=\left(a_{1}, a_{2}, \cdots, a_{k}\right)$,

The total judgment matrix is $\mathrm{R}=\left(B_{1}, B_{2}, \cdots, B_{k}\right)^{T}$

According to a model with the operator $(\Lambda, \mathrm{V})$ calculation, a comprehensive evaluation for the $A_{1 \times k} \circ R_{k \times m}=B_{1 \times m} \in \mathcal{F}(V)$ 。

According to the fuzzy comprehensive evaluation method, the coal logistics of many provinces and autonomous regions in China is evaluated accordingly, and suggestions are made according to their different development levels.

\section{Suggestions on Future Development of China 'S Coal Logistics Under New Policy Environment}

The current economic new normal policy and the energy structure of the change, making China's coal demand has been greatly affected. Coupled with the impact of foreign imports of coal, China's coal logistics development difficult. But the "one way along the" national strategy and the Department of large-scale traffic environment for the development and development of coal logistics provides a good opportunity. In this context, I am on the future development of China's coal logistics made the following recommendations:

(1) The new policy environment for China's coal logistics transformation provides a good opportunity. The reform of the majority system makes the original Ministry of Railways separate 
government, clear authority, market operation, easy to make the coal logistics out of those poor competitiveness, consumption of large, extensive coal logistics enterprises. Therefore, it is possible to promote the transformation of China's coal logistics enterprises from extensive to intensive, with the help of the large-scale traffic environment and the "one-way-one" new policy, from low to high level. This not only conforms to the requirements of China's economic development, but also to promote the development of China's coal logistics.

(2) China's long-term coal industry in the "golden decade" high-speed development period, a large number of small logistics enterprises, the market rarely have a comprehensive integrated coal logistics enterprises, coal logistics market confusion. After the railway freight reform, a number of institutions may be relatively easy and convenient for rail transport, or very convenient to transport third-party logistics enterprises, which is the opportunity for the development of third-party logistics professional coal. Therefore, we should speed up the integration of coal logistics management, and promote the development of a unified third-party efficient logistics.

(3) Huge power is easy to breed corruption and related areas of dictatorship, "along the way" and most of the traffic environment is prone to excessive rights, lax supervision, coal logistics market chaos and other issues, so pay attention to the transport sector and the railway Transport supervision, and effectively promote the development of coal logistics progress.

\section{Acknowledgments}

This paper is supported by Beijing Key Laboratory (NO: BZ0211), Beijing Intelligent Logistics System Collaborative Innovation Center and Beijing Institute of Materials Research support funding.

\section{References}

[1]. . Qianjie Ma. On coal enterprises logistics [J]. Coal economy research, 1991 (04): 28-30.

[2]. . Zhishan Ma. Reducing the cost of coal supply logistics [J]. Journal of China Coal Economic College, 1995 (01): 59-64.

[3]. Dapeng Zhang, Yong He, Shenfeng Jing. Coal enterprises logistics information to achieve the way [J]. China Coal, 2003 (03): 3.

[4]. National Development and Reform Commission. Coal Logistics Development Plan [J]. Integrated Transportation, 2014.

[5]. Yinying Tang, Jiaxin Sun.Evaluation of Customer Satisfaction of Railway "Door-to-Door" Whole Logistics Service [J]. Journal of Railway Transportation and Economy, 2015 (8): 11-16.

[6]. Dongmei Liu, Xiaoling Ku, Chuwen Bian. New Opportunities for Coal Logistics Industry [N]. Economic Daily, 2015-10-15 (014).

[7]. Zhaoyu Wang.Study on the new management model of Hebei railway government under the majority system [D]. Shijiazhuang Railway University, 2015.

[8]. Haiping Lu.Study on the Mode and Operation Mechanism of Railway Freight Embedded Social Logistics [D]. Beijing Jiaotong University, 2013.

[9]. Bo Wang. Market conditions under the conditions of railway freight competition strategy selection and optimization of transport resources [D]. Beijing Jiaotong University, 2013. 